\title{
Antecedents and consequences of adopting CLTS among tribal communities to become open defecation free: case study on Indian Swachh Bharat Abhiyan
}

\author{
Amit Adlakha ${ }^{1} \cdot$ Paritosh Pathak $^{1} \cdot$ Anup Kumar ${ }^{2} \cdot$ Prashant Pandey $^{1}$ \\ Received: 18 August 2021 / Accepted: 20 January 2022 / Published online: 11 February 2022 \\ (c) The Author(s), under exclusive licence to Springer-Verlag GmbH Germany, part of Springer Nature 2022
}

\begin{abstract}
The Swachh Bharat Mission undertaken by the Government of India (GoI) has been successful in accomplishing this objective within a short period thereby catalyzing governance following Sustainable Development Goals (SDGs). It is the responsibility of any democratic nation to ensure that its citizens have universal access to adequate and equitable sanitation. The key approach adapted to igniting a change in sanitation behavior rather than constructing toilets. An effort has been made in the study to affirm that even the marginalized sections of the society residing in tribal communities of West Bengal and Chhattisgarh have benefitted from this Government of India Mission and derived the required benefits. There is enough literature available to support the justification that civil participation holds the key for successful implementation of CLTS thereby making the communities open defecation free (ODF). It is therefore imperative to understand the behavioral transformation that takes place during the CLTS implementation. A hybrid model has been proposed in the study making use of the theory of reasoned action (TRA) and theory of planned behavior (TPB) to understand the pre-adoption and post-adoption behavior of residents. In present study, used model was empirically tested for several hypotheses. The finding reflects towards subjective norms and facilitating conditions as major determinants that ensure the continuation of intention for CLTS. They play a pivotal role in improving the health and hygiene conditions in the region and thus decrease the risk of spread of epidemic diseases.
\end{abstract}

Keywords CLTS $\cdot$ TPB $\cdot$ Health and hygiene $\cdot$ Epidemic

\section{Introduction}

Many published documents present around 892 million people practice open defecation in rural areas, among them mostly are from South Asia and Sub Saharan Africa region. As a result, Community-Led Total Sanitation (CLTS) attract policy-makers for establishing sanitation facilities to combat such issues (UNICEF and WHO). Now days, researchers focus towards nudges theory to observe and understand the behavioral change in anticipation of the welfare of the

Responsible Editor: Philippe Garrigues

Amit Adlakha

amitadlakha75@gmail.com

1 School of Management, IMS Unison University, Makkawala Greens, Dehradun, Uttarakhand 248009, India

2 IMT Nagpur, Katol Road, SH 248, Dorli, Nagpur, Maharashtra 441502, India society such as healthcare, education, and a variety of social and economic sectors (Thaler et al. 2009; Schubert 2017; Tikotsky et al. 2020; Vallgårda 2012; Weimer 2020).

In this context, CLTS depends on behavioral change and social support to end open defecation.

The acceptance of the policy as a nudge should be theoretically linked with the Technology Acceptance Model (TAM) (Davis 1989) and Theory of Planned Behavior (TPB) (Ajzen 1985). That further helps to provide the information and link to use model evaluating behavioral intention. The hypothesis has been developed based on previous literature and empirically tested to study of adoption issues of CLTS in India.

The study was conducted in two phases: in the first phase, we have studied the perception and challenges of the CLTS implementation and in the second phase, the study was conducted to evaluate the post-adoption benefits of the CLTS during the spread of COVID-19 (March to May 2020) in the Indian state of West Bengal and Chhattisgarh. The results are 
very much satisfactory, as in the post-adoption scenario, the risk of the pandemic was substantially low in the surveyed areas (Table 1).

Community-Led Total Sanitation (CLTS) is one of the major initiatives undertaken to sensitize the communities and increase their awareness regarding the maintenance of health and hygiene. The majority of recent studies conducted on CLTS have focused on the outcome of the CLTS and its impact on various performance indicators relating to health and hygiene. The top ten research papers cited during 2015-2020 have been collated, described, and presented in Table 2 (Bardosh 2015; Belizario 2015; Bulaya 2015; Crocker 2017; Garn 2017; Harter 2018; Lawrence 2016; Mara 2017; Pickering 2015; Sigler 2015). The social and behavioral impact of CLTS is another interesting area where researchers have identified the social and behavioral issues specifically relating to CLTS (Lawrence 2016; Nutor 2020; Sari 2019). Some literature studies have beautifully explored the impact of CLTS on Environmental and Social Sustainability (Belizario 2016; Head 2019; Jena 2018; Kaminsky 2015; Kresch 2020; Soboksa 2019; Youenou 2016) thereby adding a unique dimension to the study.

To give a systematic dimension to the study and explore how proper implementation of CLTS can bring about a longterm behavioral change, the study has been divided into the following sections:

The "Introduction" section presents the introduction of the study, literature review is contained in the "Literature review" section, conceptual framework and variables have been discussed in the "Conceptual framework" section,
Table 1 Summary details of selected articles

\begin{tabular}{ll}
\hline Reference date & $2020-10-12$ 23:00:39+0530 \\
Publication years & $2015-2020$ \\
Citation years & $5(2015-2020)$ \\
Papers & 89 \\
Citations & 678 \\
Citations/year & $135.60(\mathrm{acc} 1=56$, acc $2=40$, acc $5=12$, acc $10=6$, acc $20=2)$ \\
Citations/paper & 7.62 \\
Authors/paper & $1.00 / 1.0 / 1($ mean $/$ median $/$ mode $)$ \\
Age-weighted citation rate & $239.98(\mathrm{sqr}=15.49), 239.98 /$ author \\
Hirsch h-index & $13(\mathrm{a}=4.01, \mathrm{~m}=2.60,464$ cites $=68.4 \%$ coverage $)$ \\
Egghe g-index & $23(\mathrm{~g} / \mathrm{h}=1.77,557$ cites $=82.2 \%$ coverage $)$ \\
PoP hI,norm & 13 \\
PoP hI,annual & 2.60 \\
\hline
\end{tabular}

Table 2 Top ten research papers on CLTS (based on citations)

\begin{tabular}{|c|c|c|c|}
\hline Sr. & $\begin{array}{l}\text { Number of } \\
\text { citations till } \\
2020\end{array}$ & Authors & Title \\
\hline 1 & 149 & A.J. Pickering & $\begin{array}{l}\text { Effect of a Community-Led Sanitation intervention on Child Diarrhoea and Child Growth in Rural } \\
\text { Mali: A Cluster-Randomised Controlled Trial }\end{array}$ \\
\hline 2 & 72 & J. Garn & $\begin{array}{l}\text { The Impact of Sanitation Interventions on Latrine Coverage and Latrine use: A Systematic Review } \\
\text { and Meta-analysis }\end{array}$ \\
\hline 3 & 35 & V. Venkataramanan & Community-led Total Sanitation: A Mixed-methods Systematic Review of Evidence and it's Quality \\
\hline 4 & 31 & J. Crocker & Sustainability of Community-Led Total Sanitation Outcomes: Evidence from Ethiopia and Ghana \\
\hline 5 & 29 & R. Sigler & Analysis of Behavioral Change Techniques in Community-Led Total Sanitation Programs \\
\hline 6 & 25 & J. Crocker & $\begin{array}{l}\text { Impact Evaluation of Training Natural Leaders during a Community-Led Total Sanitation Interven- } \\
\text { tion: A Cluster-Randomized Field Trial in Ghana }\end{array}$ \\
\hline 7 & 23 & K. Bardosh & $\begin{array}{l}\text { Achieving "Total Sanitation" in Rural African Geographies: Poverty, Participation and Pit Latrines in } \\
\text { Eastern Zambia }\end{array}$ \\
\hline 8 & 21 & J. Crocker & Teachers and Sanitation Promotion: An Assessment of Community-Led Total Sanitation in Ethiopia \\
\hline 9 & 18 & V. Belizario & $\begin{array}{l}\text { Parasitological and Nutritional Status of School-age and Preschool-age Children in Four Villages in } \\
\text { Southern Leyte, Philippines: Lessons for Monitoring the Outcome of Community-Led Total Sanita- } \\
\text { tion }\end{array}$ \\
\hline 10 & 17 & C. Bulaya & $\begin{array}{l}\text { Preliminary evaluation of Community-Led Total Sanitation for the Control of Taenia Solium Cyst- } \\
\text { icercosis in Katete District of Zambia }\end{array}$ \\
\hline
\end{tabular}


while the "Research methodology" section contains the research methodology. The "Data collection" section contains data collection and analysis. The "Theoretical contributions and implications of research" section highlights the theoretical contributions and research implications, the "Practical insights and discussion" section provides practical insights, while the "Limitations and further research" section discusses the limitations of the study and provides direction for future research.

\section{Literature review}

The literature review was carried out in two dimensions: the first dimension discussed the genesis of CLTS while the second stressed the use of resource-based view further derived as TAM and TPB towards the adoption of social change. The first dimension was studied through bibliometric analysis using keyword search, while the theories adopted have been contextually explained to accomplish the second dimension.

\section{Genesis of CLTS}

A brief literature review on the identified keywords, including "Community-Led Total Sanitation" and "Effect of CLTS," has been presented in this section. Importantly, the literature review renders an appropriate selection of literature and helps to analyze the identified studies scientifically (Carvalho et al. 2019). The following steps have been undertaken in this study to carry out a systematic review as per PRISMA model below (Figure 1).

- Research questions

- Q1. How are TRA and TPB integrated to study the behavioral pattern during or after the implementation of CLTS?

- Q2. How are the Constructs of TAM and TPB linked with desired behavioral change?

- Q3. How are these Constructs mapped to Health and Hygiene?

Bibliometric analysis was performed on 89 research articles. Table 1 provides the summary details of selected articles.

The findings of the majority of studies about health and hygiene indicate that there is a significant improvement of the health and hygiene conditions in the communities (Biran 2018; Deng 2020; Gebremariam 2018, 2019; Gimaiyo 2019; Hürlimann 2018; Husaini 2019; Jung 2016; Mlenga 2016; Njuguna 2016; Safari 2019; Tutuanita 2019; Yeboah-Antwi 2019). The cost and benefit analysis of CLTS implementation programs reveals that CLTS interventions can yield promising cost-effective returns, particularly if rigorous follow-up post-triggering is implemented and uptake of improved latrines is achieved (Biran 2018; Cha 2020; Ficek 2019; Holm 2016; Kayoka 2019; Woode 2018).

The positive outcomes of CLTS implementation have paved the way for the preparation of policy guidelines by various social and government organizations for further diffusion of CLTS into communities thereby deriving greater benefits (Crocker et al. 2016; Harter et al. 2019; Hueso 2016; Zuin et al. 2019, 2020).

Some literature studies have emphasized the behavioral aspect of adopting CLTS but failed to support it with a theoretical justification (Alemu 2018; Balfour 2015; Bateman and Engel 2018; Holm 2016; Lawrence 2016; Sample 2016; Sigler 2015).

Previous studies conducted on CLTS have stressed the social and behavioral aspects; however, there still exists a literature gap as behavioral issues relating to the implementation of CLTS and continuation of its intention have still not been considerably explored. Therefore this research study has focused to underpin the factors affecting the continuation intention of CLTS with the help of pre-existing theories such as TAM and TPB in India.

\section{Use of TAM and TPB in the adoption of social changes}

CLTS was enforced by the various agencies to derive health benefits. Technology acceptance model and theory of planned behavior models were developed using the theory of reasoned action (TRA) to study the attitude, motivation, and subjective norms within the field of health to understand health behaviors. The use of these models is however limited by their use as Ajzen acknowledged that "some behaviors are more likely to present problems of controls than others, but we can never be certain that we will be in a position to carry out our intentions. Viewed in this light it becomes clear that strictly speaking every intention is a goal whose attainment is subject to some degree of uncertainty." The applications of technology acceptance model are widely accepted and are found in the adoption of digital services, health services, and other technological aspects of e-governance services (Alam et al. 2020; Chavoshi and Hamidi 2019; Hossain et al. 2019; Li and Shang 2020; Rubenking 2019; Tsai et al. 2019; Zhao et al. 2019), while theory of planned behavior has been instrumental in predicting the intentions to use some sociological or technological interventions (Ajzen 1985; Baker and White 2010; Fishbein and Ajzen 1975; Gagnon et al. 2012; Godin and Kok 1996; MahougbéHounsa et al. 1993; Zaremohzzabieh et al. 2019). The theory of planned behavior is used to predict the intention to use healthcare services (Godin and Kok 1996; Hu et al. 1999; Kakoko et al. 2006).

It is evident from the literature review that the use of behavioral models to study the challenges and 
Fig. 1 PRISMA model for the literature review

\section{Identification of studies via databases and registers}

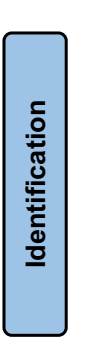

Records identified from:

Scopus and web of science

$(\mathrm{n}=150)$

Registers $(n=100)$

- Quality Criterion

QC1. Papers that discussed

CLTS performance

- Data Extraction Fields

D1: Community-Led Total

Sanitation

D2: Behaviour

D3: Effects

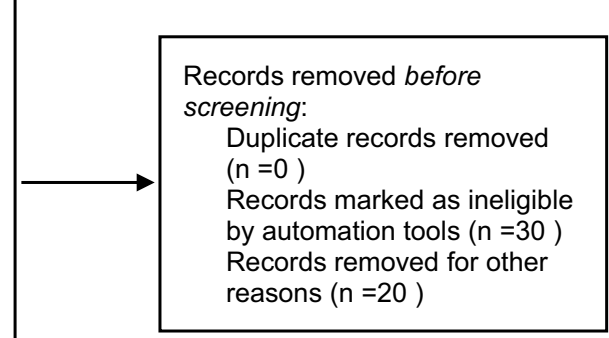

Records excluded

$(n=0)$

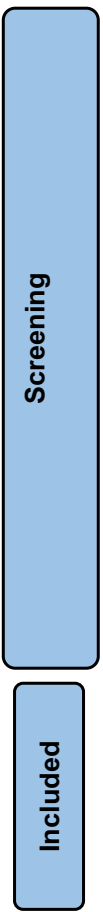
$(\mathrm{n}=100)$

Reports not retrieved $(n=0)$

Reports excluded:

- Exclusion Criteria

E1. Works not related to CLTS

E2. Works dated before 2015

Studies included in review

$(\mathrm{n}=50)$

Reports of included studies

$(\mathrm{n}=10)$ consequences ahead of CLTS implementation is less researched. An effort has been made in this study to address this issue. The constructs perceived usefulness of CLTS (PU), perceived ease of use (PEU) of CLTS, and facilitating conditions (FC) are derived from TAM, while attitude towards CLTS (AT), subjective norms (SN), and continuation intention (CI) are derived from TPB. The post-adoption constructs, improved health and hygiene (IHI), and decreased risk of epidemic (DRE) are developed by the authors to study the post-adoption effect of CLTS.

\section{Conceptual framework}

\section{CLTS context}

It includes factors like perceived usefulness and perceived ease of use that are responsible for the successful implementation of CLTS programs and increase the scale and pace of CLTS activities. These factors play a prominent role in enhancing the sanitation coverage in the tribal areas thereby making the communities open defecation 
free (ODF). They also remain instrumental in bringing about a change in behavior by sensitizing the communities and triggering emotions like disgust, shame, and respect for women, thereby creating a desire for construction and use of toilets.

\section{Individual context}

Sustainable Development Goals have highlighted the importance of the inclusion of each individual for the successful implementation of CLTS programs to have a sustainable sanitation system. This inclusion is necessary for improving the sanitation facilities and making communities open defecation free (ODF). The attitude of individuals plays a significant role in this regard as it helps in predicting the specific behavior and bringing about sustained improvements. It not only guides the individual actions but also influences their values and beliefs thereby making the process socially more acceptable.

\section{District administration context}

A holistic approach entailing the participation of each member of the community is required for the successful implementation of CLTS programs. The district administration plays a crucial role in accomplishing this objective. Robust plans are made and initiatives are undertaken in light of identified bottlenecks to improve the sanitation condition of the region. Government bodies, NGOs, and natural leaders act as facilitators and take the lead role by undertaking activities that bring about community cleanliness and improve the health and hygiene conditions.

Subjective norms that include acceptable behavioral standards play an important role at this stage to get sustained outcomes. An optimum and balanced combination of these factors ensures that no gap exists between the community initiatives and the desired behavioral change.

\section{Post adoption}

The success of CLTS programs is ultimately reflected in the "post adoption" stage when individuals change their normally exhibited behavior and develop a continued intention of adopting CLTS. This not only improves the health and hygiene conditions in the region but also decreases the risk of epidemic diseases. Health experts have highlighted the crucial role that continued intention and individual behavior play in controlling the pandemic (Anderson et al. 2020).

There is sufficient grey literature on CLTS outcomes that indicates that successful implementation of the program creates a supportive and enabling environment thereby making it more sustainable. The motivated community members act as facilitators and inspire others to change their sanitation-related behaviors. This helps in making the communities open defecation free thereby minimizing the risk of spread of epidemic diseases.

\section{Constructs and hypotheses development (1 para)}

The proposed model has been developed based on the telemedicine model proposed by $\mathrm{Chau}$ and $\mathrm{Hu}$. It encompasses three dimensions: CLTS context, individual context, and district administration context (Fig. 2). The model helps in analyzing whether continued intention towards CLTS can improve the health and hygiene conditions and decrease the risk of an epidemic or not.

The first dimension of the model "CLTS context" contains variables perceived usefulness of CLTS and perceived ease of use of CLTS, the second dimension of the model "individual context" contains the variable attitude towards CLTS while facilitating conditions and subjective norms constitute the third variable of the study, the "district administration context."

\section{Perceived usefulness of CLTS (PU) (1 para)}

Perceived usefulness is an important variable in the CLTS context; it is the degree to which an individual perceives that exhibiting a specific behavior would enhance job performance (Davis 1989). It helps in understanding the perception of individuals towards the benefits that they would realize from the successful implementation of CLTS. Davis has proposed this variable in TAM (technology acceptance model) highlighting the important role that it plays in examining the perceived usefulness of a product or service. Therefore, focus towards CLTS to improve the sanitation services and bring about effective behavioral change. Hence, it becomes imperative to understand the impact that perceived usefulness has on the attitude of individuals towards CLTS and continuation intention. The understated hypotheses have been framed to accomplish this mission:

H1a: Perceived usefulness of CLTS is positively associated with attitude towards CLTS

H1b: Perceived usefulness of CLTS is positively associated with continuation intention of CLTS

\section{Perceived ease of use of CLTS (PEU)}

For any social phenomenon to be successful, it must be user-friendly (Bhattacharjee 2001). The same holds for the successful implementation of CLTS. Ease of use signifies freedom from difficultly or great effort and emphasizes on activities that individuals undertake or resources that they invest in (Adams et al. 1992; Davis 1989, Hendrickson et al. 1993). It plays a vital role as it helps in analyzing the 


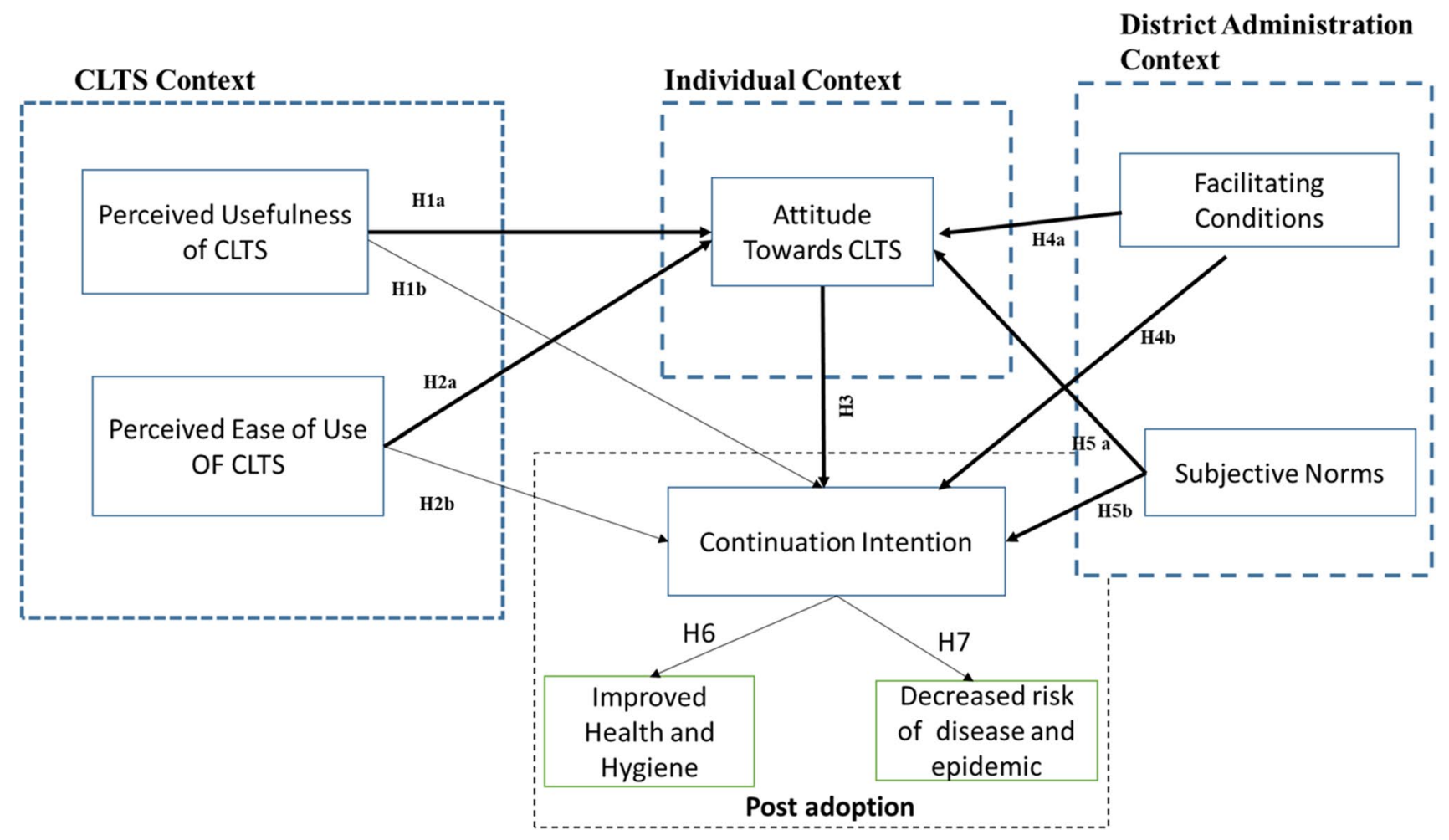

Fig. 2 Conceptual framework

perception of individuals towards CLTS. It has a direct bearing on the attitude of individuals and continuation intention towards CLTS. The understated hypotheses were developed for testing this aspect.

H2a: Perceived ease of use of CLTS is positively associated with attitude towards CLTS

H2b: Perceived ease of use of CLTS is positively associated with continuation intention of CLTS

\section{Attitude towards CLTS (AT)}

Wan et al. (2017) and Ajzen (1991) have highlighted the importance played by attitude describing it as a multidimensional concept that helps in evaluating the negative and positive aspects concerning a certain behavior exhibited by an individual. Yang et al. (2016) observed in their study that if an individual likes a specific behavior, then the intention to exhibit it becomes even higher. It may therefore be inferred that if an individual believes that CLTS is beneficial, it will strengthen his belief towards the empowering process and bring about social awakening. This action will bring about a behavior change at the community level thereby having an impact on the continuation intention. It may therefore be hypothesized that,
H3: Attitude towards CLTS is positively associated with continuation intention of CLTS

\section{Facilitating conditions (FC)}

Robust administrative capability, strong research, and participation measures act as facilitators for the successful implementation of CLTS. Community-led, people-centered, demand-driven, and incentive-based programs play a pivotal role in successfully implementing the total sanitation programs (TSPs). Government bodies, district administration, health workers, NGOs, and community leaders act as facilitators in the process. During the implementation stage, it becomes imperative to keep the community in the primary position while institutions and infrastructure should follow. This participatory approach not just ensures equitable, transparent, and efficient deliverance but also brings about sustainability. It may therefore be inferred that facilitating conditions not only increase the effectiveness of CLTS but also have a positive impact on the attitude of individuals leading to continuation intention. The following hypotheses have therefore been tested:

H4a: Facilitating conditions of CLTS is positively associated with attitude towards CLTS. 
H4b: Facilitating conditions of CLTS is positively associated with continuation intention of CLTS

\section{Subjective norms (SN)}

Subjective norms have been defined as the social pressure that individuals experience and are the outgrowth of the theory of reasoned action (Ajzen 1991). The importance of subjective injunctive norms and subjective descriptive norms as the two components of social norms has been discussed by Fishbein and Ajzen (2011). The commonly approved or disapproved behavior is a part of the subjective injunctive norm, while the subjective descriptive norms represent the behavior shown by referral groups that are important for an individual like family members, close friends, and celebrations in the specific social context (Wang et al. 2016). Community approaches bring about a behavioral change that leads to improvement in the sanitation condition of the region and provides sustainable outcomes. Through effective utilization of approaches explained by social norms theory (SNT), the health workers, community leaders, and other implementers can address the challenges posed by the social norms thereby bringing about a change in the attitude of individuals and positively affecting the continuation intention. It may therefore be hypothesized that,

H5a: Subjective norms of CLTS is positively associated with attitude towards CLTS.

H5b: Subjective norms of CLTS is positively associated with continuation intention of CLTS.

\section{Continuation intention $(\mathrm{CI})$}

For favorable outcomes, continuation of intention towards CLTS is required. Capacity-building measures and engagement of local leaders play an important role in accomplishing this objective. Following diffusion theory, local actors are trained, peer-communication is improved, and opinion leaders are made influencers to bring about a new behavior change (Rogers 2003). So, in context to aware about sanitation, hygenic status to improve and strengthen to exhibit the new behavior thereby improving the health and hygiene condition and decreasing the risk of diseases and epidemic. It may therefore be inferred that,

H6: Continuation intention of CLTS is positively associated with improved health and hygiene

H7: Continuation intention of CLTS is positively associated with decreased risk of diseases and epidemic

\section{Improved health and hygiene (IHI)}

Successful implementation of CLTS promotes both hand washing and sanitation. It significantly increases the construction of toilets thereby improving the superstructure and providing privacy to the user in each household. This plays a prominent role in making the region open defecation free. Development of WASH-related facilities, presence of soap in toilets, and covering of pits drastically improves the hygiene and health conditions in the region.

\section{Decreased risk of diseases and epidemic (DRE)}

CLTS has a marked influence on the health and life of individuals. It completely transforms the sanitation scenario and substantially improves the health condition and deteriorating quality of life of individuals, especially the poorest and the most vulnerable. This reduces the risk of the spread of an epidemic.

There is a shred of sufficient evidence to affirm that diarrhea makes children more susceptible to respiratory illness and increases the mortality rate. They also start showing other gastrointestinal illness symptoms like bloody stools. Successful implementation of CLTS reduces the prevalence of intestinal worm infections and exposure to fecal contamination due to a decrease in open defecation.

Many research studies also indicate that a contaminated environment greatly impacts environmental enteropathy. Improved sanitation plays a vital role in reducing environmental enteropathy and controlling parasite infections in young children thereby improving their growth and development.

\section{Research methodology}

The methodology adopted here is in line with the suggestions provided by Sarstedt et al. (2016) to select an appropriate version of structural equation modeling. We have adopted common factor structural equation modeling (CBSEM) as per the context and the definitions of the construct (Figure 3).

\section{Case setting}

The Swachh Bharat Mission of the Government of India (GOI) has successfully improved the sanitization condition in India within a short period. The key approach adopted by the government was Community-Led Total Sanitation (CLTS) also termed as Community Approaches to Total Sanitation (CATS). This research study was undertaken in the Dantewada District of Indian State Chattisgarh and 


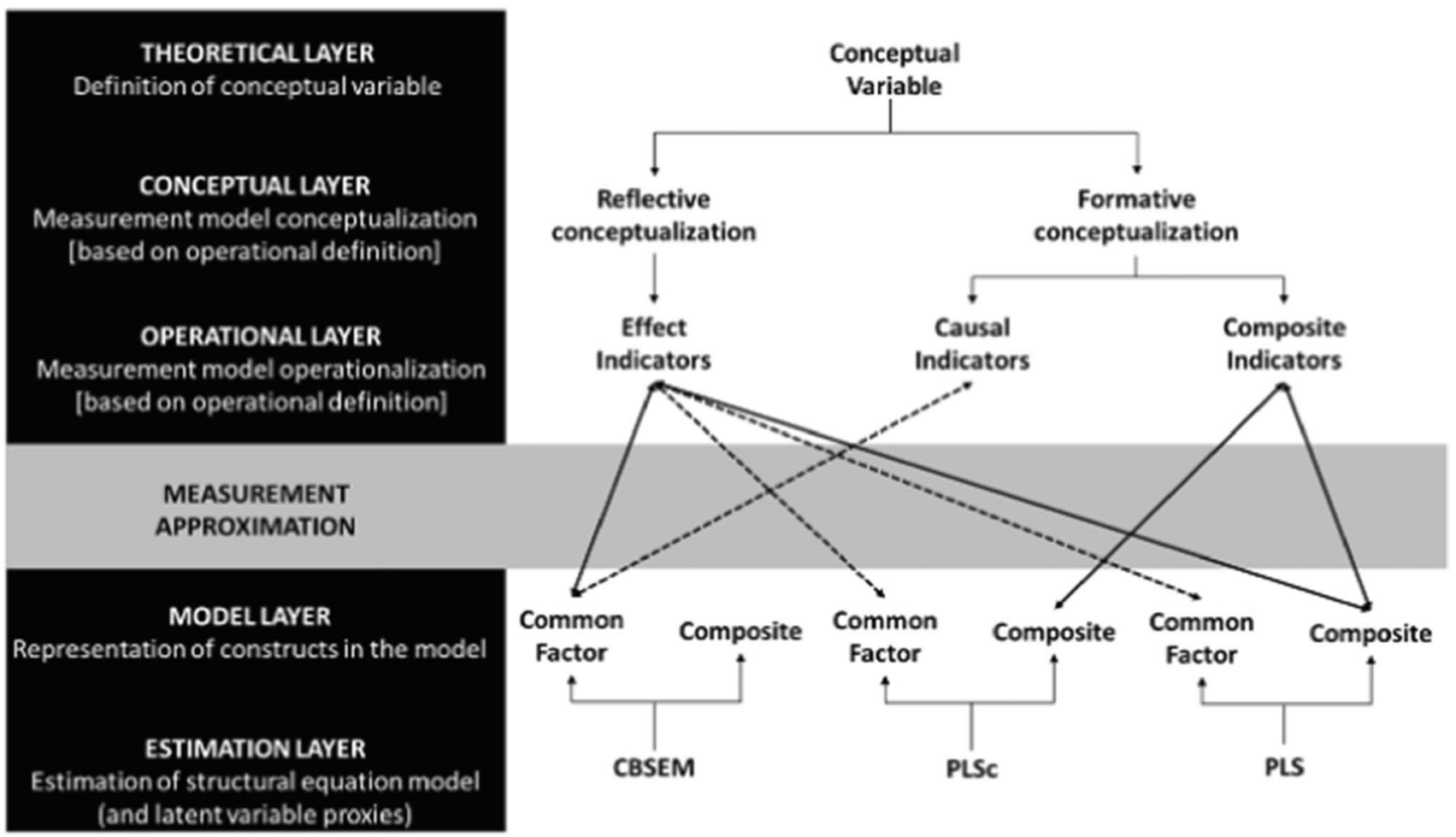

Fig. 3 Measurement and model estimation framework. 4007M. Sarstedt et al./Journal of Business Research 69 (2016) 3998-4010

Cooch Behar and Malda Districts of Indian State West Bengal.

Dantewada, also known as South Bastar District, is a small district located on the southern tip of Chhattisgarh and shares its boundaries with other Indian states, Maharashtra, Telangana, and Odisha. The district is home to nearly 0.25 million people, out of which more than $75 \%$ belong to scheduled tribes, living in and off the forests that they inhabit. Gond is the major tribe with nearly $60 \%$ population and the remaining ones include Halba, Muriya, and Maria. The district comprises 4 development blocks which cover 124 Gram Panchayats (GPs), the primary units of elected local self-government in the rural areas.

At the time of the launch of Swachh Bharat MissionGramin (SBM-G) in October 2014, the sanitation coverage of the district was less than $10 \%$, with all 124 GPs remaining to be declared as ODF. To make the entire country open defecation free (ODF) within the next 5 years was not an easy task. The Community-Led Total Sanitation (CLTS) approach was the key to this success. The impact and results of CLTS had been showing across the world, and it was considered to be the best option to make this happen. The power of collective community action and the quick and effective results of CLTS had proven that things change at a rapid pace (KAR 2008). Being a participatory and empowering approach, it engages communities in a manner that stimulates self-analysis and collective local action to put an end to open defecation (Kumar and Shukla 2011). This CLTS intervention supported by UNICEF sought to combine CLTS tools and techniques with other social mobilization methods ensuring multi-stakeholder engagement at various levels to achieve credible open defecation free (ODF) results with speed and on the scale. The key components of the strategy adopted included the following: capacity building, institutional strengthening, and ODF celebrations. A team of 30 trained CLTS facilitators was constituted to help implement SBM-G in the district. It worked well as within a year the coverage reached 40 percent and within 30 months the entire district of Dantewada was declared ODF.

Within two months Jhodiabadam, a GP with 212 households $(\mathrm{HH})$ became the first GP to be declared ODF. This GP of Gidam Development Block showed extremely positive results of CLTS implementation. The effective community triggering sessions and continuous follow-ups added to this success. The key player behind this achievement was Balram Kashyap who came up as the natural leader and paved the way for this achievement. A grand event was organized by the community wherein the district officials, public representatives, and people from other GPs were invited. It became an inspirational event for other GPs to gear up and work together to obtain ODF status for their districts; Malda is located in the northern part of West Bengal and is one of the major districts of the state. It shares an international boundary with Bangladesh on the eastern part and has a 
population of about 4 million which includes 53\% Hindus and $46 \%$ Muslims. One percent of people belong to other religions and tribal communities. There are 9 development blocks and 146 Gram Panchayats in the district. Before the implementation of CLTS, sanitation coverage in the district was a meager $40 \%$. To commence with, a habitation in the Manikchak block was selected as a pilot initiative, and after its success, the program was successfully scaled up in the entire district.

Bhutni Chandipur High school is a Sansad of Dakshin Chandipur GP of Manikchak development block in Malda district of West Bengal. It is an island surrounded by the river Ganges (Ganga). Commutation becomes a major challenge for the people residing in this area as they have to cross the river through boats, and the bad condition of the road adds further to misery as it becomes nearly impossible for residents to use it during the rainy season. Given the difficult topography, the place is also prone to heavy floods. The main source of income in the region is agriculture. Men usually work in major industrial cities like Kolkata, Delhi NCR, and Mumbai to earn a living leaving their family members behind to face drudgery.

Bhutni comprises six villages/pada with a population of around 3000. The total number of households in the Sansad is about 415 as described below in Table 3 .

Initially, CLTS training for CFs, SHG members, ICDS workers, CSPs, and other volunteers was conducted by Knowledge Links (NGO). Thereafter, an action plan for carrying out the triggering exercise was made and implemented aggressively in the Sansad. Within 3 weeks, Bhonusarkar Tola became the first ODF village. However, the momentum slowed down a bit after this achievement. Many residents expressed their inability to construct toilets citing poverty reasons and looked forward to government support in this regard. A baseline survey was done to identify the households that required financial aid to construct toilets. It was found after the survey that 7 households required financial assistance, which was extended. The financial position of the remaining households was found to be satisfactory.

Table 3 Details of households in village/pada

\begin{tabular}{lll}
\hline Sr. & Village/pada & $\begin{array}{l}\text { No. of } \\
\text { house- } \\
\text { holds }\end{array}$ \\
\hline 1. & Bhonusarkar Tola & 54 \\
2. & Chabimanjhi Tola & 125 \\
3. & Nabadeep Tola & 34 \\
4. & Biru Tola & 52 \\
5. & Sonatan Tola -1 & 95 \\
6. & Sonatan Tola -2 & 55 \\
& Total & 415 \\
\hline
\end{tabular}

They were repeatedly triggered and convinced to construct toilets on their own. The real challenge was to get toilets constructed in households that really could not afford it. To address this issue, all the SHG members, ICDS workers, CSPs, and teachers came forward and contributed money to get toilets constructed in these households.

All the residents enthusiastically participated in the CLTS implementation program and cooperated with the work teams. Despite commutation challenges owing to uneven roads and harsh weather conditions, they were successful in making the Sansad ODF.

Youth clubs also extended their support in an ample measure to achieve this objective. They dug pits, assembled the rings, arranged bamboos, and performed all other tasks that were required to support the cause. The exciting part was that all the political leaders and workers, irrespective of the political parties to which they belonged and political differences that they may have had, joined hands and came together for this purpose.

Nazardari teams regularly checked OD during the early morning hours and late evenings. Gandhigiri was practiced throughout to motivate and make the people understand the importance of ODF and curb it.

In Bhonusarkar Tola, residents also wanted to construct a community toilet for which each one of them contributed and collected around Rs. 22,000/- (twenty-two thousand rupees). They were unable to find space at a central location in the village where the community toilet was proposed. Bimla Mandol, a widow of around 70 years, came forward and donated a part of her residence for this purpose. She was recognized as a natural leader along with Sukhendu Mandal, Sameer Mandal, and Rakhi Deb.

The hard work and persistent efforts continued until the entire Sansad became ODF. Thereafter, a grand celebration was organized in which the District Magistrate, Administrative Officers, and Local Leaders participated and appreciated the efforts that were put-in by the residents to make the Sansad ODF. Sikha Mandol, the Pradhan of GP, congratulated the Sansad and requested other Sansads to take inspiration and become ODF. This was the first-ever ODF celebration in the state of West Bengal. The District Magistrate assured the availability of safe drinking water in the Sansad for improving the quality of life of residents and decreasing the spread of water-borne diseases.

The impact that the CFs, SHG members, ICDS workers, CSPs, etc. had on the residents was tremendous. They played a vital role in making the residents understand the importance of ODF and counseled them to stop practicing open defecation and use safe toilets. Their familiarity with local culture and language made it easier for them to communicate and associate with the people. This played a key role in the proper implementation of CLTS and helped in making the region ODF. 
A longitudinal study was carried out to understand the adoption issues of CLTS and its post-adoption impact. To understand the adoption issues, the latent constructs were identified using a literature review. The TRA and TPB models were found suitable to study the adoption and post-adoption issues. Exploratory factor analysis (EFA) was carried out to find out the valid number of the latent component in the questionnaire items. Based on EFA, eight latent constructs were identified as shown in the conceptual framework. Items were assigned to these latent constructs and confirmatory factor analysis (CFA) was carried out to validate the measurement of the latent factors. The methodology used (SEM) is coherent to the steps suggested by Sarstedt et al. 2016 The steps include identifying the conceptual variable and then identifying the exact methodology (CBSEM) (Figure 3).

\section{Questionnaires design}

Drawing upon TRA and TPB a 61 item questionnaire was designed to measure the latent constructs. EFA reveals that out of 61 items only 31 items were loaded adequately on the latent constructs (Table 4)

\section{Data collection}

Data was collected from 585 respondents residing in various ODF villages in Dantewada district of Chattisgarh and Malda and Cooch Behar districts of West Bengal between December 2019 and April 2020. A well-designed questionnaire making use of various rating scales was prepared in local languages to accomplish this objective. It added to the convenience of respondents and helped in obtaining their unrestrained feedback. The services of a local language translator were also taken to further facilitate this process.

\section{Structure equation modelling}

All the constructs that are measured were first-order latent constructs. The measured value against the respective items is shown in Table 3. The output of the model is shown in Figure 3. SEM was conducted using lavaan package. The output model generated is presented in Figure 4.

\section{Measurement models}

The latent constructs of the model (PU, PEU, FC, AT, $\mathrm{SN}, \mathrm{CI}, \mathrm{HY}$, and RRD) were measured using SEM using the pre-existing scale (15\% of questions were changed). The scale for the measurement of RRD was developed by the authors; prior to using the scales, a pilot study was
Table 4 Latent variable constructs

\begin{tabular}{|c|c|c|c|c|}
\hline \multicolumn{5}{|c|}{ Latent variables } \\
\hline & Estimate & Std. Err & z-value & $P(>|\mathrm{z}|)$ \\
\hline \multicolumn{5}{|l|}{$\mathrm{PU}=\sim$} \\
\hline PU1 & 1 & & & \\
\hline PU2 & 1.49 & 0.191 & 7.784 & 0 \\
\hline PU3 & 0.76 & 0.134 & 5.682 & 0 \\
\hline \multicolumn{5}{|l|}{$\mathrm{PEU}=\sim$} \\
\hline PEU1 & 1 & & & \\
\hline PEU2 & 0.599 & 0.203 & 2.955 & 0.003 \\
\hline PEU3 & 2.555 & 0.612 & 4.173 & 0 \\
\hline \multicolumn{5}{|l|}{$\mathrm{FC}=\sim$} \\
\hline FC1 & 1 & & & \\
\hline $\mathrm{FC} 2$ & 0.74 & 0.191 & 3.882 & 0 \\
\hline FC3 & 0.803 & 0.205 & 3.916 & 0 \\
\hline $\mathrm{FC} 4$ & 0.899 & 0.206 & 4.371 & 0 \\
\hline FC5 & 1.416 & 0.27 & 5.247 & 0 \\
\hline FC6 & 1.738 & 0.311 & 5.589 & 0 \\
\hline FC7 & 0.999 & 0.235 & 4.241 & 0 \\
\hline \multicolumn{5}{|l|}{$\mathrm{AT}=\sim$} \\
\hline AT1 & 1 & & & \\
\hline AT2 & 1.389 & 0.303 & 4.591 & 0 \\
\hline AT3 & 1.627 & 0.345 & 4.718 & 0 \\
\hline AT4 & 2.328 & 0.458 & 5.082 & 0 \\
\hline \multicolumn{5}{|l|}{$\mathrm{SN}=\sim$} \\
\hline SN1 & 1 & & & \\
\hline $\mathrm{SN} 2$ & 0.816 & 0.084 & 9.716 & 0 \\
\hline SN3 & 0.407 & 0.059 & 6.842 & 0 \\
\hline SN4 & 0.42 & 0.064 & 6.531 & 0 \\
\hline \multicolumn{5}{|l|}{$\mathrm{CI}=\sim$} \\
\hline CI1 & 1 & & & \\
\hline $\mathrm{CI} 2$ & 1.784 & 0.367 & 4.862 & 0 \\
\hline $\mathrm{CI} 3$ & 0.927 & 0.247 & 3.757 & 0 \\
\hline \multicolumn{5}{|l|}{$\mathrm{HY}=\sim$} \\
\hline HY1 & 1 & & & \\
\hline \multicolumn{5}{|l|}{$\mathrm{RRD}=\sim$} \\
\hline RRD1 & 1 & & & \\
\hline RRD2 & 0.799 & 0.264 & 3.031 & 0.002 \\
\hline RRD3 & 1.408 & 0.295 & 4.765 & 0 \\
\hline RRD4 & 1.012 & 0.303 & 3.345 & 0.001 \\
\hline RRD5 & 1.546 & 0.323 & 4.787 & 0 \\
\hline RRD6 & 0.663 & 0.231 & 2.874 & 0.004 \\
\hline
\end{tabular}

conducted to observe its reliability. The authors tested multiple models for a better fit. The measurement loadings of the few constructs (highlighted in yellow color) in model 1 were below or above the required cutoff and were hence deleted in model 2. It is evident that model 2 exhibits a good model fit and better reliability (Table 5). It is a good fit model for further analysis. 


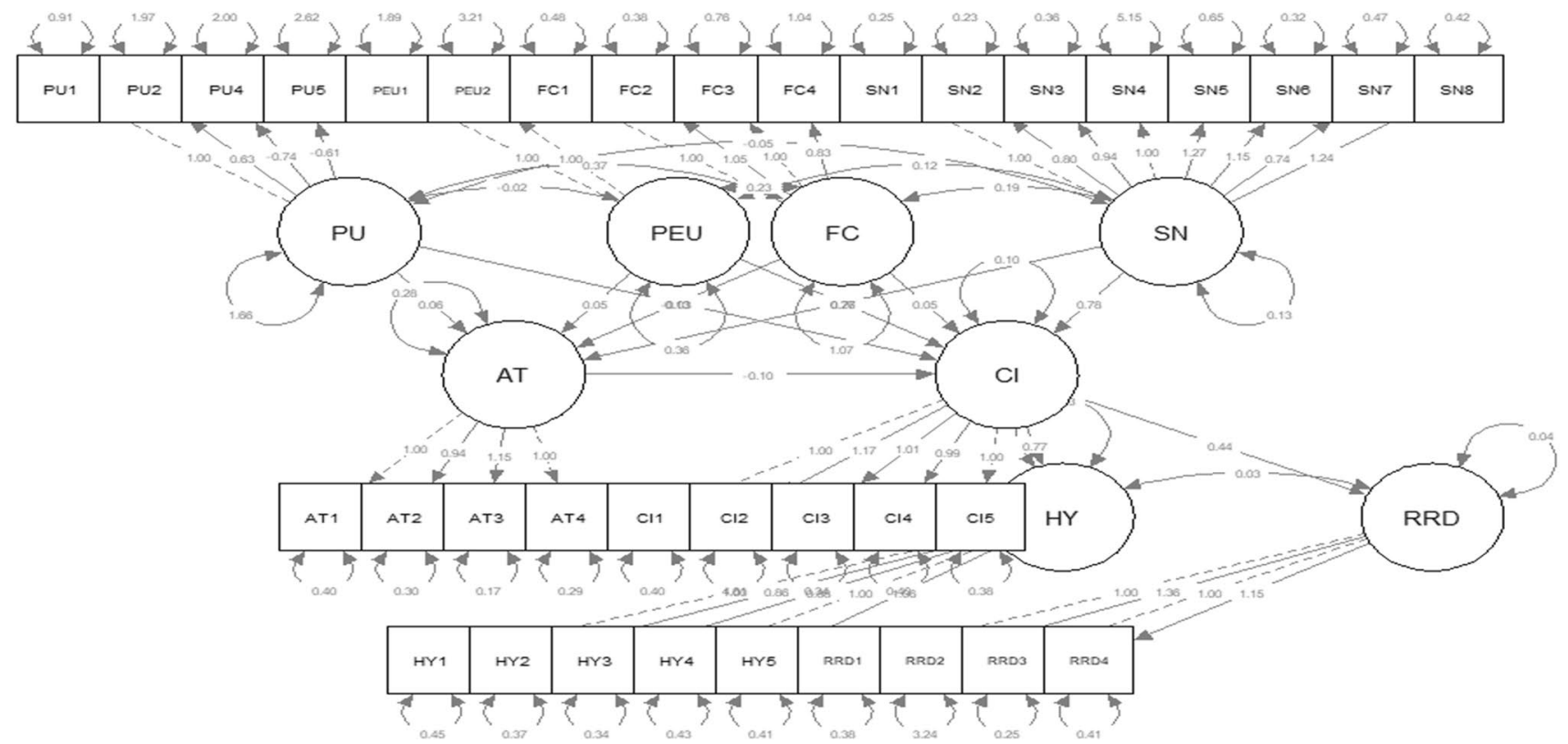

Fig. 4 Structure equation modeling

\section{Model validity}

The goodness of model 2 has rendered adequate model validity (Table 6); the authors followed the steps to check the common method bias and discriminant validity of the CBSEM as suggested by Hair et al. (2006). Harman's single factor test was run to examine the common method bias. It revealed that the maximum variance explained by the considered study variables was $29.11 \%$. This proves that common method bias is not an issue since the retrieved variance explanation value is much less than the recommended threshold value of $50 \%$.

Confirmatory factor analysis was carried out for examining the validity and reliability of the study constructs. To begin with, the composite reliability and Cronbach's alpha values for study measures were greater than 0.70 (Fornell and Larcker 1981).

\section{Path model}

The path model is based on model 2 which has shown an adequate model fitness and validity. The results of the path model are shown in Figure 5. The path model shows the results of the hypotheses and their significance (Refer to Table 9 for hypothesis results). The regression results of the path model are provided in Table 8 .

\section{Data analysis and results}

Discriminant validity of the latent constructs is the extent to which a latent variable discriminates from other latent variables. The AVE assessment is the extent of variation that a construct can explain in the observed variables to which it is theoretically related. If the AVE for each construct is greater than its shared variance with any other construct, discriminant validity is supported (refer to Table 7) (Farrell 2010) (Tables 8 and 9).

\section{Group analysis}

The adoption of CLTS was also analyzed in groups (males and females). The results of group analysis are shown in Table 10. The results show that the subjective norms are significant in the male group, while they are not significant in the female group at $95 \%$ level of confidence; the same difference could be observed for perceived ease of use (refer to the highlighted numbers in Table 10).

\section{Theoretical contributions and implications of research}

The study has attempted to explore the crucial role that Community-Led Total Sanitation plays in improving the health and hygiene in tribal communities and decreasing the risk of spread of epidemic diseases. The proposed hybrid model can yield outstanding results provided it is strategized and implemented with a judicious mix of responsiveness, transparency, and accountability. There is sufficient evidence in the study to affirm that CLTS as a participatory approach sensitizes the community and makes it aware of the ill effects that poor sanitation has on the health and life of people. 
Table 5 Measurement models

\begin{tabular}{|c|c|c|c|c|}
\hline \multirow[t]{2}{*}{ Latent variables } & \multicolumn{4}{|l|}{ Model 1} \\
\hline & Estimate & Std. Err & $z$-value & $P(>|z|)$ \\
\hline \multicolumn{5}{|l|}{$\mathrm{PU}=\sim$} \\
\hline PU1 & 1 & & & \\
\hline PU2 & 0.688 & 0.072 & 9.505 & 0.000 \\
\hline PU3 & -0.325 & 0.063 & -5.16 & 0.000 \\
\hline PU4 & -0.796 & 0.079 & -10.038 & 0.000 \\
\hline PU5 & -0.555 & 0.075 & -7.429 & 0.000 \\
\hline PU6 & -0.131 & 0.066 & -1.986 & 0.047 \\
\hline \multicolumn{5}{|l|}{$\mathrm{PEU}=\sim$} \\
\hline PEU1 & 1 & & & \\
\hline PEU2 & 1.146 & 0.29 & 3.958 & 0.000 \\
\hline \multicolumn{5}{|l|}{$\mathrm{FC}=\sim$} \\
\hline FC1 & 1 & & & \\
\hline $\mathrm{FC} 2$ & 1.169 & 0.07 & 16.797 & 0.000 \\
\hline $\mathrm{FC} 3$ & 1.575 & 0.083 & 19.071 & 0.000 \\
\hline FC4 & 1.278 & 0.074 & 17.22 & 0.000 \\
\hline \multicolumn{5}{|l|}{$\mathrm{AT}=\sim$} \\
\hline AT1 & 1 & & & \\
\hline AT2 & 1.235 & 0.086 & 14.431 & 0.000 \\
\hline AT3 & 1.495 & 0.095 & 15.759 & 0.000 \\
\hline AT4 & 1.559 & 0.1 & 15.607 & 0.000 \\
\hline \multicolumn{5}{|l|}{$\mathrm{SN}=\sim$} \\
\hline SN1 & 1 & & & \\
\hline $\mathrm{SN} 2$ & 0.829 & 0.095 & 8.723 & 0.000 \\
\hline SN3 & 0.984 & 0.116 & 8.498 & 0.000 \\
\hline SN4 & 2.121 & 0.359 & 5.907 & 0.000 \\
\hline SN5 & 1.586 & 0.165 & 9.597 & 0.000 \\
\hline SN6 & 1.374 & 0.132 & 10.409 & 0.000 \\
\hline SN7 & 0.77 & 0.116 & 6.633 & 0.000 \\
\hline SN8 & 1.454 & 0.145 & 10.011 & 0.000 \\
\hline \multicolumn{5}{|l|}{$\mathrm{CI}=\sim$} \\
\hline CI1 & 1 & & & \\
\hline $\mathrm{CI} 2$ & 1.989 & 0.393 & 5.059 & 0.000 \\
\hline $\mathrm{CI} 3$ & 1.788 & 0.202 & 8.845 & 0.000 \\
\hline CI4 & 1.867 & 0.211 & 8.857 & 0.000 \\
\hline CI5 & 2.474 & 0.264 & 9.358 & 0.000 \\
\hline \multicolumn{5}{|l|}{$\mathrm{HY}=\sim$} \\
\hline HY1 & 1 & & & \\
\hline HY2 & 1.085 & 0.131 & 8.262 & 0.000 \\
\hline HY3 & 1.076 & 0.129 & 8.333 & 0.000 \\
\hline HY4 & 1.521 & 0.167 & 9.101 & 0.000 \\
\hline HY5 & 1.33 & 0.153 & 8.689 & 0.000 \\
\hline \multicolumn{5}{|l|}{$\mathrm{RRD}=\sim$} \\
\hline RRD1 & 1 & & & \\
\hline RRD2 & 2.21 & 1.15 & 1.921 & 0.055 \\
\hline RRD3 & 5.204 & 1.709 & 3.044 & 0.002 \\
\hline RRD4 & 4.725 & 1.546 & 3.057 & 0.002 \\
\hline \multirow[t]{2}{*}{ Latent variables } & Model 2 & & & \\
\hline & Estimate & Std. Err & $z$-value & $P(>|z|)$ \\
\hline
\end{tabular}

Table 5 (continued)

\begin{tabular}{|c|c|c|c|c|}
\hline \multicolumn{5}{|l|}{$\mathrm{PU}=\sim$} \\
\hline PU1 & 1 & & & \\
\hline PU2 & 0.627 & 0.069 & 9.119 & 0.000 \\
\hline PU4 & -0.738 & 0.076 & -9.768 & 0.000 \\
\hline PU5 & -0.606 & 0.074 & -8.239 & 0.000 \\
\hline \multicolumn{5}{|l|}{ PEU = } \\
\hline PEU1 & 1 & & & \\
\hline PEU2 & 1 & & & \\
\hline \multicolumn{5}{|l|}{$\mathrm{FC}=\sim$} \\
\hline $\mathrm{FC} 1$ & 1 & & & \\
\hline FC2 & 1.0 & 0.04 & 26.705 & 0.000 \\
\hline FC3 & 1 & & & \\
\hline $\mathrm{FC} 4$ & 0.83 & 0.048 & 17.244 & 0.000 \\
\hline \multicolumn{5}{|l|}{$\mathrm{AT}=\sim$} \\
\hline AT1 & 1 & & & \\
\hline AT2 & 0.942 & 0.046 & 20.483 & 0.000 \\
\hline AT3 & 1.0 & 0.046 & 24.812 & 0.000 \\
\hline AT4 & 1 & & & \\
\hline \multicolumn{5}{|l|}{$\mathrm{SN}=\sim$} \\
\hline SN1 & 1 & & & \\
\hline $\mathrm{SN} 2$ & 0.798 & 0.08 & 9.926 & 0.000 \\
\hline SN3 & 0.941 & 0.098 & 9.605 & 0.000 \\
\hline SN4 & 1 & & & \\
\hline SN5 & 1.0 & 0.132 & 9.609 & 0.000 \\
\hline SN6 & 1.0 & 0.104 & 11.034 & 0.000 \\
\hline SN7 & 0.737 & 0.1 & 7.357 & 0.000 \\
\hline SN8 & 1.0 & 0.117 & 10.663 & 0.000 \\
\hline \multicolumn{5}{|l|}{$\mathrm{CI}=\sim$} \\
\hline CI1 & 1 & & & \\
\hline $\mathrm{CI} 2$ & 1.0 & 0.203 & 5.783 & 0.000 \\
\hline $\mathrm{CI} 3$ & 1.00 & 0.068 & 14.829 & 0.000 \\
\hline CI4 & 0.993 & 0.071 & 14.013 & 0.000 \\
\hline CI5 & 1 & & & \\
\hline \multicolumn{5}{|l|}{$\mathrm{HY}=\sim$} \\
\hline HY1 & 1 & & & \\
\hline HY2 & 0.862 & 0.079 & 10.918 & 0.000 \\
\hline HY3 & 0.878 & 0.077 & 11.336 & 0.000 \\
\hline HY4 & 1 & & & \\
\hline HY5 & 1.0 & 0.088 & 12.039 & 0.000 \\
\hline \multicolumn{5}{|l|}{$\mathrm{RRD}=\sim$} \\
\hline RRD1 & 1 & & & \\
\hline RRD2 & 1.0 & 0.307 & 4.444 & 0.000 \\
\hline RRD3 & 1 & & & \\
\hline RRD4 & 1.0 & 0.133 & 8.649 & 0.000 \\
\hline
\end{tabular}

It is today that nudge is widely deployed by the policymakers for the establishment of sanitation facilities. Behavioral operations management is an emerging area of research that makes use of human experiments especially when it is imperative to enforce nudge for the society at large (Bendoly et al. 2006). CLTS is a nudge to improve the sanitation 
Table 6 Fit indices

\begin{tabular}{|c|c|c|c|}
\hline Fit indices' analysis of the research model & Model fit & $\begin{array}{l}\text { Reference index } \\
\text { (Upadhyay and Kumar } \\
\text { 2020) }\end{array}$ & Source \\
\hline$\chi^{2} / \mathrm{df}$ & 2.16 & $<3$ & $\begin{array}{l}\text { Barrett (2007); Falke et al. (2020); Oberski (2014); Rosseel } \\
\text { et al. (2017) }\end{array}$ \\
\hline Goodness-of-fit index (GFI) & 0.8973 & $>0.9$ & $\begin{array}{l}\text { Barrett (2007); Falke et al. (2020); Oberski (2014); Rosseel } \\
\text { et al. (2017) }\end{array}$ \\
\hline Adjusted goodness-of-fit index (AGFI) & 0.8777 & $>0.9$ & $\begin{array}{l}\text { Barrett (2007); Falke et al. (2020); Oberski (2014); Rosseel } \\
\text { et al. (2017) }\end{array}$ \\
\hline Normed fit index (NFI) & 0.894 & $>0.9$ & $\begin{array}{l}\text { Barrett (2007); Falke et al. (2020); Oberski (2014); Rosseel } \\
\text { et al. (2017) }\end{array}$ \\
\hline Bentler-Bonnet non-normed fit index (NNFI) & 0.933 & $>0.9$ & $\begin{array}{l}\text { Barrett (2007); Falke et al. (2020); Oberski (2014); Rosseel } \\
\text { et al. (2017) }\end{array}$ \\
\hline Tucker-Lewis index (TLI) & 0.933 & $>0.9$ & $\begin{array}{l}\text { Barrett (2007); Falke et al. (2020); Oberski (2014); Rosseel } \\
\text { et al. (2017) }\end{array}$ \\
\hline Comparative fit index (CFI) & 0.94 & $>0.9$ & $\begin{array}{l}\text { Barrett (2007); Falke et al. (2020); Oberski (2014); Rosseel } \\
\text { et al. (2017) }\end{array}$ \\
\hline $\begin{array}{l}\text { Standardized root mean square error of } \\
\text { approximation (SRMR) }\end{array}$ & 0.049 & $<0.08$ & $\begin{array}{l}\text { Barrett (2007); Falke et al. (2020); Oberski (2014); Rosseel } \\
\text { et al. (2017) }\end{array}$ \\
\hline
\end{tabular}

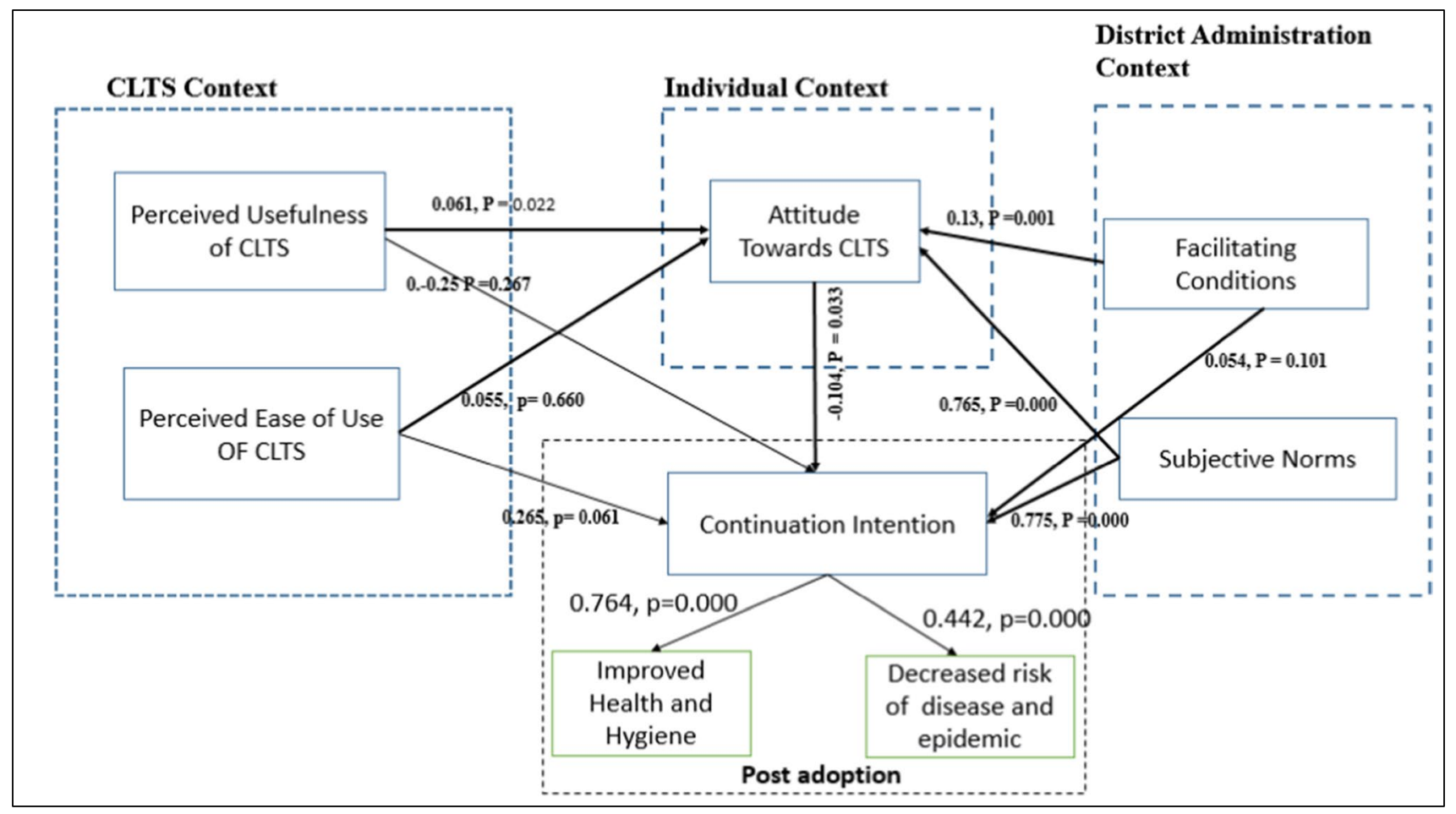

Fig. 5 Path model

conditions in tribal communities and decrease the risk of spread of epidemic diseases. The results of the study indicate that even if the perceived ease of use of practicing CLTS is not significantly associated with the attitude towards CLTS, the perceived usefulness of this nudge is playing a prominent role in its adoption. Facilitating conditions and subjective norms are two important behavioral aspects that are essential to managing this nudge.

The results indicate that though facilitating conditions may not be significantly associated with the continuation intention of CLTS, they have a marked influence on the attitude towards CLTS. It is also evident that subjective norms 
Table 7 Correlation matrix (diagonal value represents AVE)

\begin{tabular}{lllllllll}
\hline & PU & PEU & FC & AT & SN & CI & HY & RRD \\
\hline PU & $\mathbf{0 . 4 6}$ & & & & & & & \\
PEU & -0.02915 & 0.56 & & & & & & \\
FC & 0.27562 & 0.362513 & $\mathbf{0 . 6 2}$ & & & & & \\
AT & 0.130328 & 0.352131 & 0.466467 & $\mathbf{0 . 7 7}$ & & & & \\
SN & -0.1041 & 0.547508 & 0.498815 & 0.539544 & $\mathbf{0 . 8 8}$ & & \\
CI & -0.11906 & 0.613298 & 0.420721 & 0.318205 & 0.716614 & $\mathbf{0 . 7 6}$ & & \\
HY & -0.10863 & 0.559552 & 0.383851 & 0.290319 & 0.653814 & 0.912366 & $\mathbf{0 . 9 7}$ & \\
RRD & -0.08694 & 0.447834 & 0.307213 & 0.232355 & 0.523276 & 0.730205 & 0.884681 & $\mathbf{0 . 9 0}$ \\
\hline
\end{tabular}

The bold values signify the validity and perceived usefulness of CLTS are playing a partial mediating role between attitude towards CLTS and the continuation intention of the CLTS.

Table 8 Regression analysis

\begin{tabular}{|c|c|c|c|c|}
\hline \multirow[t]{2}{*}{ Regressions } & \multicolumn{4}{|l|}{ Model 1} \\
\hline & Estimate & Std. Err & $z$-value & $P(>|\mathrm{z}|)$ \\
\hline \multicolumn{5}{|l|}{$\mathrm{AT} \sim$} \\
\hline PU & 0.039 & 0.021 & 1.908 & 0.056 \\
\hline PEU & 0.065 & 0.107 & 0.615 & 0.539 \\
\hline $\mathrm{FC}$ & 0.095 & 0.038 & 2.51 & 0.012 \\
\hline SN & 0.688 & 0.141 & 4.892 & 0.000 \\
\hline \multicolumn{5}{|l|}{$\mathrm{CI} \sim$} \\
\hline PU & -0.008 & 0.014 & -0.604 & 0.546 \\
\hline PEU & 0.157 & 0.093 & 1.689 & 0.091 \\
\hline AT & -0.075 & 0.039 & -1.952 & 0.051 \\
\hline FC & 0.036 & 0.026 & 1.41 & 0.159 \\
\hline $\mathrm{SN}$ & 0.418 & 0.108 & 3.882 & 0.000 \\
\hline \multicolumn{5}{|l|}{$\mathrm{HY} \sim$} \\
\hline CI & 1.03 & 0.146 & 7.074 & 0.000 \\
\hline \multicolumn{5}{|l|}{ RRD } \\
\hline CI & 0.167 & 0.059 & 2.847 & 0.004 \\
\hline \multirow[t]{2}{*}{ Regressions: } & Model 2 & & & \\
\hline & Estimate & Std. Err & $z$-value & $P(>|z|)$ \\
\hline \multicolumn{5}{|l|}{$\mathrm{AT} \sim$} \\
\hline PU & 0.061 & 0.026 & 2.298 & 0.022 \\
\hline PEU & 0.055 & 0.124 & 0.441 & 0.660 \\
\hline $\mathrm{FC}$ & 0.13 & 0.038 & 3.455 & 0.001 \\
\hline SN & 0.765 & 0.16 & 4.782 & 0.000 \\
\hline \multicolumn{5}{|l|}{$\mathrm{CI} \sim$} \\
\hline $\mathrm{PU}$ & -0.025 & 0.023 & -1.11 & 0.267 \\
\hline PEU & 0.265 & 0.142 & 1.872 & 0.061 \\
\hline $\mathrm{AT}$ & -0.104 & 0.049 & -2.133 & 0.033 \\
\hline $\mathrm{FC}$ & 0.054 & 0.033 & 1.64 & 0.101 \\
\hline SN & 0.775 & 0.161 & 4.814 & 0.000 \\
\hline \multicolumn{5}{|l|}{$\mathrm{HY} \sim$} \\
\hline $\mathrm{CI}$ & 0.767 & 0.055 & 13.957 & 0.000 \\
\hline \multicolumn{5}{|l|}{$\mathrm{RRD} \sim$} \\
\hline CI & 0.442 & 0.043 & 10.214 & 0.000 \\
\hline
\end{tabular}

\section{Practical insights and discussion}

An effort has been made in this study to analyze the perception and challenges of CLTS implementation and the postadoption benefits that can be derived through it. The major factors that affect the CLTS implementation were studied, and a hybrid model based on the technology acceptance model (TAM) and theory of planned behavior (TPB) that would help ascertain the pre-adoption and post-adoption behavior was established. The results of the study indicate that CLTS triggers the community to adopt better sanitation and hygiene practices. The community takes ownership of the entire program to improve the sanitation conditions within the region. Once the community understands the importance of better sanitation and hygiene practices, the usage of toilets is automatically ensured. Since the community leads the program and most of the people voluntarily help each other, a lot of labor cost gets saved. CLTS is scalable and an easy to replicate process; residents of neighboring communities and villages visualize and feel the changes that are offered by open defecation free environment. This automatically triggers the residents of nearby villages and habitations to collectively wish and make their habitations open defecation free.

The process brings about a change in the behavior of the community, feelings of disgust and shame trigger the individuals, and they collectively decide to end open defecation and adopt better practices thereby preventing personal, social, economic, and environmental hazards that are caused due to open defecation.

CLTS is a community-based inclusive approach through which the marginalized and other vulnerable individuals, families, and groups are brought together into the program. Since the approach focuses on totality, every person of the community is connected and involved in the social transformation towards sanitation and hygiene. The collective behavioral change, construction of good quality toilets, and their usage are the key drivers that make the CLTS approach sustainable. Once individuals change existing habits and adopt better hygienic practices, they continue throughout their life. The benefits accrued further strengthen the roots 
Table 9 Hypotheses

\begin{tabular}{lll}
\hline Hypothesis & & Results \\
\hline H1a & Perceived usefulness of CLTS is positively associated with attitude towards CLTS & Supported \\
H1b & Perceived usefulness of CLTS has positively associated with continuation intention of CLTS & Not significant \\
H2a & Perceived ease of use of CLTS is positively associated with attitude towards CLTS & Not significant \\
H2b & Perceived ease of use of CLTS has positively associated continuation intention of CLTS & Not significant \\
H3 & Attitude towards CLTS is positively associated with continuation intention of CLTS & Supported but opposite \\
H4a & Facilitating conditions of CLTS is positively associated with attitude towards CLTS & Supported \\
H4b & Facilitating conditions of CLTS is positively associated with continuation intention of CLTS & Not significant \\
H5a & Subjective norms of CLTS is positively associated with attitude towards CLTS & Supported \\
H5b & Subjective norms of CLTS is positively associated with continuation intention of CLTS & Supported \\
H6 & Continuation intention of CLTS is positively associated with improved health and hygiene & Supported \\
H7 & Continuation intention of CLTS is positively associated with decreased risk of diseases and epidemic & Supported \\
\hline
\end{tabular}

Table 10 Group analysis

\begin{tabular}{|c|c|c|c|c|}
\hline \multirow[t]{2}{*}{ Regressions } & & Group 2 & Female (122) & \\
\hline & Estimate & Std. Err & $z$-value & $P(>|z|)$ \\
\hline \multicolumn{5}{|l|}{$\mathrm{AT} \sim$} \\
\hline PU & 0.023 & 0.096 & 0.242 & 0.809 \\
\hline PEU & 0.042 & 0.282 & 0.147 & 0.883 \\
\hline $\mathrm{FC}$ & 0.177 & 0.085 & 2.09 & 0.037 \\
\hline $\mathrm{SN}$ & 0.427 & 0.257 & 1.662 & 0.097 \\
\hline \multicolumn{5}{|l|}{$\mathrm{CI} \sim$} \\
\hline PU & 0.028 & 0.087 & 0.328 & 0.743 \\
\hline PEU & 0.802 & 0.36 & 2.227 & 0.026 \\
\hline AT & -0.055 & 0.106 & -0.522 & 0.602 \\
\hline $\mathrm{FC}$ & -0.034 & 0.088 & -0.39 & 0.697 \\
\hline $\mathrm{SN}$ & 0.062 & 0.288 & 0.216 & 0.829 \\
\hline \multicolumn{5}{|l|}{$\mathrm{HY} \sim$} \\
\hline CI & 0.829 & 0.123 & 6.753 & 0.000 \\
\hline \multicolumn{5}{|l|}{$\mathrm{RRD} \sim$} \\
\hline $\mathrm{CI}$ & 0.564 & 0.102 & 5.512 & 0.000 \\
\hline \multirow[t]{2}{*}{ Regressions: } & Group 1 & Male (463) & & \\
\hline & Estimate & Std. Err & $z$-value & $P(>|z|)$ \\
\hline \multicolumn{5}{|l|}{$\mathrm{AT} \sim$} \\
\hline PU & 0.046 & 0.024 & 1.898 & 0.058 \\
\hline PEU & 0.054 & 0.137 & 0.393 & 0.694 \\
\hline $\mathrm{FC}$ & 0.097 & 0.043 & 2.235 & 0.025 \\
\hline SN & 1.041 & 0.234 & 4.444 & 0.000 \\
\hline \multicolumn{5}{|l|}{$\mathrm{CI} \sim$} \\
\hline PU & -0.042 & 0.022 & -1.898 & 0.058 \\
\hline PEU & 0.267 & 0.166 & 1.609 & 0.108 \\
\hline AT & -0.078 & 0.057 & -1.354 & 0.176 \\
\hline $\mathrm{FC}$ & 0.059 & 0.039 & 1.503 & 0.133 \\
\hline SN & 0.802 & 0.235 & 3.41 & 0.001 \\
\hline \multicolumn{5}{|l|}{$\mathrm{HY} \sim$} \\
\hline CI & 0.734 & 0.058 & 12.668 & 0.000 \\
\hline \multicolumn{5}{|l|}{$\mathrm{RRD} \sim$} \\
\hline CI & 0.373 & 0.044 & 8.48 & 0.000 \\
\hline
\end{tabular}

of such collective transformation at the community level at large thereby improving the health and hygiene conditions and decreasing the risk of spread of epidemic diseases.

\section{Limitations and further research}

The study provides sufficient evidence that sustained behavior change can bring about community transformation through the implementation of CLTS thereby enhancing the health and hygiene conditions and decreasing the risk of epidemic diseases. However, despite these advantages, certain limitations pose challenges and hamper the successful implementation of CLTS. To make the habitation open defecation free effective triggering at the community level is required. The failure to do so makes it even difficult to facilitate collective decision-making and improve the sanitation conditions.

Community facilitators also have an important role to play towards the success of this process. They should be experienced and must possess a proper understanding of the culture, practices, beliefs, values, languages, and other behavioral aspects. Inexperienced facilitators may not be able to make the required impact at the community level and desired results may not be achieved.

In addition to the above, political and social interference or resistance may prove to be a serious bottleneck during the CLTS implementation stage. Such interferences often mislead the community and slow down the ongoing momentum. The success of CLTS largely depends on how effectively the community leads the program within its habitation; any external interference may disturb the entire process.

Acknowledgements We would like to acknowledge School of Management, IMS Unison University, Dehradun, Uttarakhand, India, for their support providing workplace and infrastructure of this project work. 
Author contribution Amit Adlakha: Supervision, conceptualization, visualization, editing, and financial aid.

Paritosh Pathak: Sample collection, methodology, data curation, interpretation, writing-original draft preparation, and visualization.

Anup Kumar: Software application, analysis, visualization, and editing

Prashant Pandey: Interpretation and analysis for environmental aspects and draft preparation.

Data availability Not applicable.

\section{Declarations}

Ethics approval and consent to participate No ethical issue.

Consent for publication Not applicable in this section.

Competing interests The authors declare no competing interests.

\section{References}

Adams DA, Nelson RR, Todd PA (1992) Perceived usefulness, ease of use, and usage of information technology: A replication. MIS quarterly pp. 227-247

Ajzen I (1985) From intentions to actions: a theory of planned behavior. In: Action control. Springer, pp 11-39)

Ajzen I (1991) The theory of planned behavior. Organizational behavior and human decision processes 50(2):179-211

Alam MZ, Hoque MR, Hu W, Barua Z (2020) Factors influencing the adoption of mHealth services in a developing country: a patientcentric study. Int J Inf Manag 50:128-143. https://doi.org/10. 1016/j.ijinfomgt.2019.04.016

Alemu F (2018) The role of psychological factors in predicting latrine ownership and consistent latrine use in rural Ethiopia: a crosssectional study. BMC Public Health 18(1). https://doi.org/10. 1186/s12889-018-5143-0

Anderson RM, Heesterbeek H, Klinkenberg D, Hollingsworth TD (2020) How will country-based mitigation measures influence the course of the COVID-19 epidemic?. The lancet 395(10228):931-934

Baker RK, White KM (2010) Predicting adolescents' use of social networking sites from an extended theory of planned behaviour perspective. Comput Hum Behav 26(6):1591-1597. https://doi. org/10.1016/j.chb.2010.06.006

Balfour N (2015) CLTS in fragile and insecure contexts. Waterlines 34(3):269-276. https://doi.org/10.3362/1756-3488.2015.025

Bardosh K (2015) Achieving "total sanitation" in rural African geographies: poverty, participation and pit latrines in Eastern Zambia. Geoforum 66:53-63. https://doi.org/10.1016/j.geoforum.2015. 09.004

Barrett P (2007) Structural equation modelling: adjudging model fit. Personal Individ Differ 42(5):815-824

Bateman M, Engel S (2018) To shame or not to shame-that is the sanitation question. Dev Policy Rev 36(2):155-173. https://doi. org/10.1111/dpr.12317

Belizario V (2015) Parasitological and nutritional status of schoolage and preschool-age children in four villages in Southern Leyte, Philippines: lessons for monitoring the outcome of Community-Led Total Sanitation. Acta Trop 141:16-24. https://doi. org/10.1016/j.actatropica.2014.09.008
Belizario VY (2016) High burden of soil-transmitted helminthiases in preschool-age children in Masbate: a decade of implementation of the integrated helminth control program in the Philippines. Southeast Asian J Trop Med Public Health 47(4):667679 Retrieved from https://www.scopus.com/inward/record.uri? partnerID $=\mathrm{HzOxMe} 3 \mathrm{~b} \& \mathrm{scp}=85024483218$ \&origin=inward

Bendoly E, Donohue K, Schultz KL (2006) Behavior in operations management: Assessing recent findings and revisiting old assumptions. J Oper Manag 24(6):737-752

Biran A (2018) A cluster-randomized trial to evaluate the impact of an inclusive, community-led total sanitation intervention on sanitation access for people with disabilities in Malawi. Am J Trop Med Hyg 98(4):984-994. https://doi.org/10.4269/ajtmh. 17-0435

Bhattacharjee S, Bhanderi MK, Choudhary D, Akoijam SK, Thangjam BS, SinghN DKT, Narayanan K (2001) Public Health Law 207 PH. Ananthanarayanan Special Article Introducing Intradermal Rabies Vaccination in India: Paradigm Shift for the Better 209

Bulaya C (2015) Preliminary evaluation of Community-Led Total Sanitation for the control of Taenia solium cysticercosis in Katete District of Zambia. Vet Parasitol 207(3):241-248. https://doi.org/ 10.1016/j.vetpar.2014.12.030

Carvalho NR, Ruivo P, de Carvalho L M, Fonseca C, Fevereiro M, Carvalho P, Peleteiro MC (2019) First description of a fatal equine infection with Halicephalobus gingivalis in Portugal. Relevance for public health. Veterinary Medicine and Science 5(2):222-229

Cha S (2020) Benefits and costs of a community-led total sanitation intervention in rural Ethiopia- a trial-based ex post economic evaluation. Int J Environ Res Public Health 17(14):1-21. https:// doi.org/10.3390/ijerph17145068

Chavoshi A, Hamidi H (2019) Social, individual, technological and pedagogical factors influencing mobile learning acceptance in higher education: a case from Iran. Telematics Inform 38:133165. https://doi.org/10.1016/j.tele.2018.09.007

Crocker J (2017) Sustainability of community-led total sanitation outcomes: evidence from Ethiopia and Ghana. Int J Hyg Environ Health 220(3):551-557. https://doi.org/10.1016/j.ijheh.2017.02. 011

Crocker J, Geremew A, Atalie F, Yetie M, Bartram J (2016) Teachers and sanitation promotion: an assessment of community-led total sanitation in Ethiopia. Environ Sci Technol 50(12):6517 Retrieved from https://search.proquest.com/docview/1799227567?accou ntid=120671

Davis FD (1989) Perceived usefulness, perceived ease of use, and user acceptance of information technology. MIS Q pp. 319-340

Deng ZH (2020) The control of clonorchiasis in Guangdong province, southern China. Acta Trop 202. https://doi.org/10.1016/j.actat ropica.2019.105246

Falke A, Schröder N, Endres H (2020) A first fit index on estimation accuracy in structural equation models. J Bus Econ 90(2):277-302

Farrell AM (2010) Insufficient discriminant validity: a comment on Bove, Pervan, Beatty, and Shiu (2009). J Bus Res 63(3):324-327

Ficek F (2019) Comprehending practitioners' assessments of community-led total sanitation. Health Promot Int 34(6). https://doi.org/ 10.1093/heapro/day070

Fishbein M, Ajzen I (1975) Belief, attitude, intention, and behaviour: an introduction to theory and research. Addision-Wesley. Fransson, N., and Garling, Reading, pp 369-382

Fishbein M, Ajzen I (2011) Predicting and changing behavior: The reasoned action approach. Psychology press

Fornell C, Larcker DF (1981) Evaluating structural equation models with unobservable variables and measurement error. J Mark Res 18(1):39-50

Gagnon MP, Orruno E, Asua J, Abdeljelil AB, Emparanza J (2012) Using a modified technology acceptance model to evaluate 
healthcare professionals' adoption of a new telemonitoring system. Telemed E-Health 18(1):54-59

Garn J (2017) The impact of sanitation interventions on latrine coverage and latrine use: a systematic review and meta-analysis. Int $\mathbf{J}$ Hyg Environ Health 220(2):329-340. https://doi.org/10.1016/j. ijheh.2016.10.001

Gebremariam B (2018) Assessment of community led total sanitation and hygiene approach on improvement of latrine utilization in Laelay Maichew District, North Ethiopia. A comparative crosssectional study. PLoS One 13(9). https://doi.org/10.1371/journ al.pone. 0203458

Gebremariam B (2019) Effect of community led total sanitation and hygiene (CLTSH) implementation program on latrine utilization among adult villagers of North Ethiopia: a cross-sectional study. BMC Res Notes 12(1). https://doi.org/10.1186/ s13104-019-4519-2

Gimaiyo G (2019) Can child-focused sanitation and nutrition programming improve health practices and outcomes? Evidence from a randomised controlled trial in Kitui County, Kenya. BMJ Glob Health 4(1). https://doi.org/10.1136/bmjgh-2018-000973

Godin G, Kok G (1996) The theory of planned behavior: a review of its applications to health-related behaviors. Am J Health Promot 11(2):87-98

Hair JF, Black WC, Babin BJ, Anderson RE, Tatham RL (2006) Multivariate data analysis (vol. 6): Pearson Prentice Hall Upper Saddle River

Harter M (2018) How does Community-Led Total Sanitation (CLTS) affect latrine ownership? A quantitative case study from Mozambique. BMC Public Health 18(1). https://doi.org/10.1186/ s12889-018-5287-y

Harter M, Lilje J, Mosler H-J (2019) Role of implementation factors for the success of community-led total sanitation on latrine coverage. a case study from rural Ghana. Environ Sci Technol 53(9):5466$10.1021 /$ acs.est.9b01055

Head JR (2019) Integration of water, sanitation, hygiene and nutrition programming is associated with lower prevalence of child stunting and fever in Oromia, Ethiopia. Afr J Food Agric Nutr Dev 19(4):14971-14993. https://doi.org/10.18697/ajfand.87.17785

Hendrickson AR, Massey PD, Cronan TP (1993) On the test-retest reliability of perceived usefulness and perceived ease of use scales. MIS quarterly $227-230$

Holm R (2016) Adopters and non-adopters of low-cost household latrines: a study of corbelled pit latrines in 15 districts of Malawi. Sustainability (Switzerland) 8(10). https://doi.org/10.3390/su810 0917

Hossain A, Quaresma R, Rahman H (2019) Investigating factors influencing the physicians' adoption of electronic health record (EHR) in healthcare system of Bangladesh: an empirical study. Int J Inf Manag 44:76-87. https://doi.org/10.1016/j.ijinfomgt.2018.09.016

Hu PJ, Chau PYK, Sheng ORL, Tam KY (1999) Examining the technology acceptance model using physician acceptance of telemedicine technology. J Manag Inf Syst 16(2):91-112

Hueso A (2016) Policy processes in rural sanitation: the case of CLTS in India. Iberoamerican J Dev Stud 5(2):108-124 Retrieved from https://www.scopus.com/inward/record.uri?partnerID=HzOxM e 3 b\&scp $=84994691825$ \& origin $=$ inward

Hürlimann E (2018) Effect of an integrated intervention package of preventive chemotherapy, community-led total sanitation and health education on the prevalence of helminth and intestinal protozoa infections in Côte d'Ivoire. Parasit Vectors 11(1). https://doi.org/ 10.1186/s13071-018-2642-x

Husaini (2019) The effect of the community led total sanitation (Clts) method on the event of diarrhea in balita in banjar district. Indian J Public Health Res Dev 10(12):1872-1874. https://doi.org/10. 37506/v10/i12/2019/ijphrd/192140
Jena A (2018) Effects of community sanitation program on the awareness of environmental sustainability in Assam, India. Int Q Community Health Educ 39(1):51-61. https://doi.org/10. $1177 / 0272684 X 18787150$

Jung S (2016) The effects of improved sanitation on diarrheal prevalence, incidence, and duration in children under five in the SNNPR State, Ethiopia: study protocol for a randomized controlled trial. Trials 17(1). https://doi.org/10.1186/ s13063-016-1319-z

Kakoko DC, Åstrøm AN, Lugoe WL, Lie GT (2006) Predicting intended use of voluntary HIV counselling and testing services among Tanzanian teachers using the theory of planned behaviour. Soc Sci Med 63(4):991-999. https://doi.org/10.1016/j. socscimed.2006.02.016

Kaminsky J (2015) Theorizing the internal social sustainability of sanitation organizations. J Constr Eng Manag 141(2). https:// doi.org/10.1061/(ASCE)CO.1943-7862.0000933

Kar S, Moura JM (2008) Distributed consensus algorithms in sensor networks with imperfect communication: Link failures and channel noise. IEEE Transactions on Signal Processing 57(1):355-369

Kayoka C (2019) Lasting results: a qualitative assessment of efforts to make community-led total sanitation more inclusive of the needs of people with disabilities in Rumphi District, Malawi. Disabil Health J 12(4):718-721. https://doi.org/10.1016/j.dhjo. 2019.05.007

Kresch EP (2020) Externalities and spillovers from sanitation and waste management in urban and rural neighborhoods. Appl Econ Perspect Policy 42(3):395-420. https://doi.org/10.1093/ aepp/ppz024

Kumar N, Shukla JP (2011) CLTS in the context of a countrywide programme in India: Public good, private good. L Mehta y $S$ (eds.). Shit Matters. The Potential of Community-Led Total Sanitation. Practical Action Publishing. Rugby

Lawrence JJ (2016) Beliefs, behaviors, and perceptions of community-led total sanitation and their relation to improved Sanitation in Rural Zambia. Am J Trop Med Hyg 94(3):553-562. https:// doi.org/10.4269/ajtmh.15-0335

Li Y, Shang H (2020) Service quality, perceived value, and citizens' continuous-use intention regarding e-government: empirical evidence from China. Inf Manag 57(3):103197. https://doi.org/ 10.1016/j.im.2019.103197

MahougbéHounsa A, Godin G, Alihonou E, Valois P, Girard J (1993) An application of Ajzen's theory of planned behaviour to predict mothers' intention to use oral rehydration therapy in a rural area of Benin. Soc Sci Med 37(2):253-261. https://doi.org/10. 1016/0277-9536(93)90459-H

Mara D (2017) The elimination of open defecation and its adverse health effects: a moral imperative for governments and development professionals. J Water Sanitation Hyg Dev 7(1):1-12. https://doi.org/10.2166/washdev.2017.027

Mlenga D (2016) Community led total sanitation for community based disaster risk reduction: a case for non-input humanitarian relief. Jamba: J Disaster Risk Stud 8(2):1-8. https://doi.org/10. 4102/jamba.v8i2.183

Njuguna J (2016) Effect of eliminating open defecation on diarrhoeal morbidity: an ecological study of Nyando and Nambale subcounties, Kenya. BMC Public Health 16(1). https://doi.org/10. 1186/s12889-016-3421-2

Nutor JJ (2020) Influence of toilet access on antiretroviral adherence intention among pregnant and breastfeeding women who are HIV-positive and enrolled in Option B+. Health Care Women Int. https://doi.org/10.1080/07399332.2020.1746791

Oberski D (2014) lavaan. survey: an R package for complex survey analysis of structural equation models. J Stat Softw 57(1):1-27 
Pickering AJ (2015) Effect of a community-led sanitation intervention on child diarrhoea and child growth in rural Mali: a clusterrandomised controlled trial. Lancet Glob Health 3(11). https:// doi.org/10.1016/S2214-109X(15)00144-8

Rosseel Y, Oberski D, Byrnes J, Vanbrabant L, Savalei V, Merkle E, ..., Barendse M (2017) Package 'lavaan.' Retrieved June, 17, 2017

Rubenking B (2019) Emotion, attitudes, norms and sources: exploring sharing intent of disgusting online videos. Comput Hum Behav 96:63-71. https://doi.org/10.1016/j.chb.2019.02.011

Rogers EM, Singhal A (2003) Empowerment and communication: Lessons learned from organizing for social change. Annals of the International Communication Association 27(1):67-85

Safari J (2019) Lessons learned from the national sanitation campaign in Njombe district, Tanzania. J Water Sanitation Hyg Dev 9(4):754-764. https://doi.org/10.2166/washdev.2019.274

Sample ED (2016) Understanding the drivers of sanitation behaviour in riverine communities of Niger Delta, Nigeria: the case of Odi and Kaiama communities. J Water Sanitation Hyg Dev 6(3):491-499. https://doi.org/10.2166/washdev.2016.050

Sari S (2019) Community-led total sanitation program attain to increase knowledge, attitude and intention but fail to change the community's behavior; case study in urban slum area in Bandung municipality. IOP Conf Ser Earth Environ Sci 248(1). https://doi. org/10.1088/1755-1315/248/1/012007

Sarstedt M, Hair JF, Ringle CM, Thiele KO, Gudergan SP (2016) Estimation issues with PLS and CBSEM: where the bias lies! J Bus Res 69(10):3998-4010

Schubert C (2017) Green nudges: Do they work? Are they ethical? Ecol Econ 132:329-342

Sigler R (2015) Analysis of behavioral change techniques in community-led total sanitation programs. Health Promot Int 30(1):16-28. https://doi.org/10.1093/heapro/dau073

Soboksa NE (2019) Water supply, sanitation and hygiene interventions and childhood diarrhea in Kersa and Omo Nada districts of Jimma Zone, Ethiopia: a comparative cross-sectional study. J Health Popul Nutr 38(1). https://doi.org/10.1186/s41043-019-0205-1

Thaler RH, Sunstein Robert Sugden Taylor CR, Sugden R (2009) On nudging: a review of nudge: improving decisions about health, wealth and happiness. Int J Econ Bus Int J Econ Bus. https://doi. org/10.1080/13571510903227064

Tikotsky A, Pe'er E, Feldman Y (2020) Which nudges do businesses like? Managers' attitudes towards nudges directed at their business or at their customers. J Econ Behav Organ 170:43-51

Tsai J-M, Cheng M-J, Tsai H-H, Hung S-W, Chen Y-L (2019) Acceptance and resistance of telehealth: the perspective of dual-factor concepts in technology adoption. Int J Inf Manag 49:34-44. https://doi.org/10.1016/j.ijinfomgt.2019.03.003

Tutuanita N (2019) Sanitation, open defecation, and Diarrhea in Tangerang, Banten, Indonesia, in early 2017: a cross-sectional epidemiological study. J Int Dent Med Res 12(1):368-371 Retrieved from https://www.scopus.com/inward/record.uri?partnerID= $\mathrm{HzOxMe} 3 \mathrm{~b} \& \mathrm{scp}=85069505066$ \& origin $=$ inward

Upadhyay P, Kumar A (2020) The intermediating role of organizational culture and internal analytical knowledge between the capability of big data analytics and a firm's performance. Int J Inf Manag 52:102100. https://doi.org/10.1016/j.ijinfomgt.2020.102100

Vallgårda S (2012) Nudge - a new and better way to improve health? Health Policy 104(2):200-203

Wang S, Fan J, Zhao D, Yang S, Fu Y (2016) Predicting consumers' intention to adopt hybrid electric vehicles: using an extended version of the theory of planned behavior model. Transportation 43(1):123-143

Wang Y, Wan Q, Huang Z, Huang L, Kong F (2017) Psychometric properties of multidimensional scale of perceived social support in Chinese parents of children with cerebral palsy. Frontiers in Psychology $\mathrm{p} 8$

Wang H, Lane GM, Wang ND, Crosier R, Campbell BSAT, Gosling SD (2016) Using smartphones to collect behavioral data in psychological science: Opportunities, practical considerations, and challenges. Perspectives on Psychological Science 11(6):838-854

Weimer DL (2020) When are nudges desirable? Benefit Validity when preferences are not consistently revealed. Public Adm Rev 80(1):118-126

Woode P (2018) Cost and effectiveness of water, sanitation and hygiene promotion intervention in Ghana: the case of four communities in the Brong Ahafo region. Heliyon 4(10). https://doi.org/10.1016/j. heliyon.2018.e00841

Yeboah-Antwi K (2019) Improving sanitation and hygiene through community-led total sanitation: the Zambian experience. Am J Trop Med Hyg 100(4):1005-1012. https://doi.org/10.4269/ajtmh. 18-0632

Youenou B (2016) Impact of untreated urban waste on the prevalence and antibiotic resistance profiles of human opportunistic pathogens in agricultural soils from Burkina Faso. Environ Sci Pollut Res 23(24):25299-25311. https://doi.org/10.1007/ s11356-016-7699-5

Zaremohzzabieh Z, Ahrari S, Krauss SE, Samah AA, Meng LK, Ariffin Z (2019) Predicting social entrepreneurial intention: a meta-analytic path analysis based on the theory of planned behavior. J Bus Res 96:264-276. https://doi.org/10.1016/j.jbusres.2018.11.030

Zhao Y, Li K, Zhang L (2019) A meta-analysis of online health adoption and the moderating effect of economic development level. Int J Med Inform 127:68-79. https://doi.org/10.1016/j.ijmedinf. 2019.04.015

Zuin V, Delaire C, Peletz R, Cock-Esteb A, Khush R, Albert J (2019) Policy diffusion in the rural sanitation sector: lessons from Community-Led Total Sanitation (CLTS). World Dev 124:1. https:// doi.org/10.1016/j.worlddev.2019.104643

Zuin V, Delaire C, Peletz R, Cock-Esteb A, Khush R, Albert J et al (2020) Policy diffusion in the rural sanitation sector: lessons from Community-Led Total Sanitation (CLTS). World Dev 245:112705. https://doi.org/10.1016/j.socscimed.2019.112705

Publisher's note Springer Nature remains neutral with regard to jurisdictional claims in published maps and institutional affiliations. 